\title{
Hong Kong Consensus Statements for the Management of Unresectable Hepatocellular Carcinoma
}

\author{
Tom Tan-To Cheung ${ }^{a}$ Philip Chong-Hei Kwok ${ }^{b}$ Stephen Chan ${ }^{c}$ \\ Chin-Cheung Cheung $^{d}$ Ann-Shing Lee ${ }^{e}$ Victor Lee $^{f}$ Hoi-Ching Cheng ${ }^{g}$ \\ Nam-Hung Chiah Charing C.N. Chong ${ }^{i}$ Tak-Wing Laij Ada L.Y. Lawk \\ Mai-Yee Luk $^{f}$ Chi Chung Tong ${ }^{f}$ Thomas C.C. Yau'

\begin{abstract}
${ }^{a}$ Department of Surgery, Queen Mary Hospital, The University of Hong Kong, Hong Kong, China; ${ }^{b}$ Department of Radiology and Imaging, Queen Elizabeth Hospital, Hong Kong, China; ' Department of Clinical Oncology, Prince of Wales Hospital, The Chinese University of Hong Kong, Hong Kong, China; d Department of Surgery, Tuen Mun Hospital, Hong Kong, China; ${ }^{e}$ Department of Clinical Oncology, Tuen Mun Hospital, Hong Kong, China; ${ }^{f}$ Department of Clinical Oncology, Queen Mary Hospital, The University of Hong Kong, Hong Kong, China; 9 Department of Clinical Oncology, Queen Elizabeth Hospital,

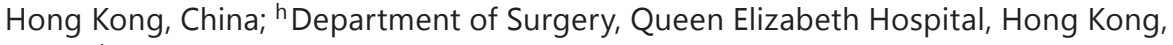
China; 'Department of Surgery, The Chinese University of Hong Kong, Hong Kong, China; jDepartment of Surgery, Princess Margaret Hospital, Hong Kong, China; ${ }^{k}$ Clinical Oncology, Pamela Youde Nethersole Eastern Hospital, Hong Kong, China; 'Department of Medicine and Surgery, Queen Mary Hospital, The University of Hong Kong, Hong Kong, China
\end{abstract}

\section{Keywords}

Consensus · Hepatocellular carcinoma · Unresectable HCC · Hong Kong

\begin{abstract}
Background: Hepatocellular carcinoma $(\mathrm{HCC})$ is highly prevalent in Hong Kong due to the high prevalence of chronic hepatitis B infection. Liver cancer is the fourth most common cancer and the third most common cause of cancer death. Due to the high case load, there is a high level of local expertise in treating HCC, and the full spectrum of treatment modalities is available. This document summarizes how these modalities should be used based on the latest evidence. Summary: In 2 meetings held in early 2017, a multidisciplinary group of Hong Kong clinicians, including liver surgeons, interventional radiologists, clinical oncologists, and medical oncologists, met to update local consensus statements for management of HCC. These statements are based on the latest evidence and give detailed guidance on how to deploy these modalities, in particular for cases of $\mathrm{HCC}$ which are not suited to surgical resection.
\end{abstract}




\section{Liver Cancer}

\begin{tabular}{l|l}
\hline Liver Cancer 2018;7:40-54 \\
\hline DOI: 10.1159/000485984 & $\begin{array}{l}\text { (c) 2018 S. Karger AG, Basel } \\
\text { www.karger.com/lic }\end{array}$ \\
\hline
\end{tabular}

Cheung et al.: Consensus Statements for the Management of Unresectable HCC

Key Messages: These statements give detailed information on how to decide if a patient is a candidate for resection, methods to improve candidacy for resection, and guidance for use of various nonsurgical interventions to manage patients ineligible for resection.

(c) 2018 S. Karger AG, Basel

\section{Introduction}

Hepatocellular carcinoma (HCC) accounts for $80 \%$ of liver cancer and is the third most common cause of cancer death in the Asia Pacific region [1]. In Hong Kong, liver cancer is the fourth commonest cancer and the third commonest cause of cancer death [2], and HCC is highly prevalent in Hong Kong due to the high prevalence of chronic hepatitis B infection.

Treating HCC is challenging, as the patient needs to be treated for both a highly malignant tumor with a propensity for venous invasion, and impaired liver function or cirrhosis. HCC is treated in Hong Kong by surgical approaches, including liver resection, liver transplantation, and local ablation, and nonsurgical approaches such as transcatheter arterial chemoembolization (TACE), transcatheter arterial radioembolization (TARE), stereotactic body radiation therapy (SBRT), systemic chemotherapy, and the multikinase inhibitor sorafenib.

Several staging systems have been developed and applied to HCC to provide prognosis and guide treatment. The Barcelona Clinic Liver Cancer (BCLC) staging system [3] is widely endorsed and used in Western countries, but is not commonly used in Asia. BCLC staging was developed in Western countries where hepatitis C virus (HCV) infection, alcohol-related cirrhosis, and nonalcoholic fatty liver disease are the main attributable factors for HCC. In Asian populations, $\mathrm{HCC}$ is associated with endemic hepatitis B virus (HBV) infection, resulting in a higher case volume. The treatment recommendations from BCLC staging are perceived by physicians in Asia as too conservative, and with the high level of local expertise, a more aggressive treatment approach is taken, particularly the broader use of surgical resection.

The Hong Kong Liver Cancer (HKLC) staging system is a locally developed prognostic classification scheme that includes treatment guidance for Asian patients with HCC, validated using data from 3,856 patients treated in Hong Kong [4]. Additional local guidance comes from consensus recommendations published by Poon et al. [5] in 2015. The objective of this new consensus document is to update the 2015 recommendations according to the latest data, with a focus on treatment of unresectable HCC.

\section{Methods}

In 2 meetings held in February and March 2017, a multidisciplinary group of Hong Kong clinicians hepatobiliary surgeons, medical oncologists, clinical oncologists, and interventional radiologists - met to formulate consensus statements on management of unresectable HCC. Local clinicians known to have a special clinical and/or research interest in HCC management were invited from the universities and major public hospitals of Hong Kong to form a panel that was broadly representative in terms of institutions and specialties.

Consensus statements were developed by designated group members prior to the meetings. Statements and the supporting evidence were presented to the group members and the statements modified according to the feedback. Each statement was assessed using a Likert scale (1 - Accept completely; 2 - Accept with some reservations; 3 - Accept with major reservations; 4 - Reject with reservations; 5 - Reject completely), and voting was performed anonymously to encourage independent responses. Acceptance was defined as $80 \%$ of the group accepting a statement completely or with some reservations. Where a consensus was not met, statements were revised and voted on until a consensus was met. The group evaluated each statement's level of evidence as per the 2011 Oxford criteria [6]. Where applicable, the levels are given in parentheses at the end of the statements. 


\section{Consensus Statements}

\section{The Role of Liver Cancer Staging Systems}

1. The BCLC staging system is not conventionally used to stratify HCC patients for treatment in Hong Kong.

2. The HKLC staging system provides a better prognostic classification and treatment algorithm than BCLC in a HBV-predominant population (Level 2).

3. In patients from an HBV-predominant population with intermediate and locally advanced HCC, HKLC staging is better than BCLC in stratifying patients into various treatment modalities (Level 2).

The HKLC staging system incorporates parameters such as Eastern Cooperative Oncology Group (ECOG) status, presence of extrahepatic vascular invasion/metastasis, tumor size and number of nodules to stage liver cancer and guide treatment. HKLC staging has been compared with BCLC using data from almost 4,000 patients with HCC treated in Hong Kong between 1995 and 2008 [4]. HKLC staging showed superior ability to distinguish between patients with specific overall survival (OS) times and HKLC-assigned subsets of BCLC intermediateand advanced-stage patients to more aggressive treatments which improved survival [4]. A comparison of BCLC and HKLC in 668 Chinese HCC patients confirmed HKLC to be superior for prognosis [7], and a comparison in a North American cohort of patients who received intra-arterial therapy for unresectable HCC found HKLC outperformed BCLC for survival separation, survival time, calibration, and discrimination[8].

\section{Definition of Unresectable}

4. Liver resection should be considered as a first-line curative treatment for HKLC intermediate-stage HCC, and with satisfactory liver function reserve.

5. Liver resection should be considered in HKLC locally advanced HCC when adequate function of future liver remnant (FLR) is anticipated.

6. Resection of both isolated extrahepatic metastasis and hepatic tumor may be considered in selected patients.

7. Selected patients with bilobar tumor may benefit from combined resection of the predominant tumor and resection or ablation of the contralateral nodules (Level 4).

Approximately $45 \%$ of patients with HCC in Hong Kong receive some form of surgery, a proportion that would fall to approximately $25 \%$, if the more conservative BCLC recommendations were followed. Major and minor resection carries a mortality risk of approximately 5 and $1-2 \%$, respectively. While transplantation is an effective option, donation rates in Hong Kong are lower than in the West.

Indications for partial hepatectomy include unilobar disease, and absence of invasion into the portal vein or inferior vena cava. Some patients with thrombus of the portal vein main branch have received resection and portal vein reconstruction [9], but long-term survival data are limited; such patients may be candidates for yttrium 90 (Y-90) radioembolization. Patients with severe chronic illness or decompensated cirrhosis are not resectable.

Prior to resection, liver function should be assessed with tests of bilirubin, alanine aminotransferase, aspartate aminotransferase, alkaline phosphatase, platelet count, Child-Pugh grade, and indocyanine green (ICG) retention. ICG retention should be performed in addition to Child-Pugh grading to better assess liver function in the future remnant [10]. The volume of the FLR should be assessed, with $20 \%$ considered acceptable for normal liver [10], 30\% for postchemotherapy patients [11], and 40\% for patients with cirrhosis [12]. Combined resection and intraoperative radiofrequency ablation (RFA) was analyzed in a retrospective case comparison study of 200 patients with HCC, with combination therapy found to be safe and effective in multifocal HCC, and an attractive option for bilobar disease [13]. The efficacy of 


\section{Liver

resection of predominant tumor and combined liver resection and RFA is supported by a cohort study that included 1,198 patients over a 20-year period [14].

In Hong Kong, the primary treatment for bilobar tumor is resection with the aim of achieving adequate liver reserve after the operation. Tumor size of $10 \mathrm{~cm}$ or more is not considered a contraindication to surgery; resection in patients with tumors of this size is supported by a retrospective study comparing surgical outcomes in patients grouped by tumor size which found a median survival of 38.0 months in patients with curative resection of solitary HCC larger than $10 \mathrm{~cm} \mathrm{[15].}$

8. For patients with inadequate FLR, portal vein embolization (PVE) can increase the chance of resection (Level 3).

PVE can be used to induce atrophy in the part of the liver to be resected and compensatory hypertrophy in the remnant part. A systematic review of 40 studies including 2,144 patients found that PVE is effective in increasing the FLR, allowing resection in patients who may otherwise be ineligible [16]. ALPPS, an alternative procedure, can produce more rapid liver growth, but with a higher risk of mortality compared with PVE (approximately $10 \mathrm{vs.}$ $2 \%$, respectively) $[16,17]$.

\section{The Role of Local Ablation}

9. Local ablation is an acceptable alternative to resection for small $\mathrm{HCC}(<3 \mathrm{~cm})$ in ChildPugh A/B patients (Level 4).

10. For resectable tumors $3-5 \mathrm{~cm}$ in patients with Child-Pugh A liver function, resection is the preferred option over ablation (Level 1).

A 2013 systematic review and meta-analysis covering 2 randomized controlled trials (RCTs) and 10 non-RCTs comparing RFA and resection in early-stage HCC up to $5 \mathrm{~cm}$ in size found that disease-free survival and OS are better with resection compared with RFA [18]; however, ablation was associated with fewer posttreatment complications and shorter hospital stays [18].

11. For HCC nodules $3-5 \mathrm{~cm}$ in diameter, the combination of TACE and ablation may be more beneficial than ablation alone (Level 1).

12. For solitary tumors $5-7 \mathrm{~cm}$, ablation combined with TACE may be beneficial in selected patients (Level 4).

A recent meta-analysis of 7 RCTs found that RFA plus TACE significantly improved survival rates at 1, 3, and 5 years compared with RFA alone in patients with tumors $>3 \mathrm{~cm}$, but not in patients with tumors $<3 \mathrm{~cm}$ [19]. The safety and efficacy of RFA in larger HCC was assessed in a study that compared the safety and efficacy of RFA in patients with smaller $(\leq 3$ $\mathrm{cm}$ ) and larger (3.1-8.0 cm) tumors, finding RFA to be safe and effective for larger HCC [20].

13. RFA via the surgical approach is preferred when tumor location incurs a high risk of biliary or visceral injury by percutaneous approach, and may offer a survival benefit for patients with large HCC $>3 \mathrm{~cm}$ (Level 3).

14. An ablative margin of $<5 \mathrm{~mm}$ was significantly correlated with local recurrence in HCC

(Level 4).

Percutaneous and surgical RFA have been compared in 162 patients with HCC in dangerous locations. Curative rates were similar in both groups, but the incidence of severe postoperative complications and local tumor progression was lower in the surgical RFA group [21]. Another case series found that while complete ablation rates are similar when performing the percutaneous approach versus the surgical approach for HCC $(3.1-5 \mathrm{~cm}), 1$ and 3-year survival rates are significantly higher in patients managed via the surgical approach [22]. A case series of patients who received computed tomography-guided RFA found an ablation zone with a minimal margin uniformly larger than $5 \mathrm{~mm}$ was associated with the best local tumor control [23]. 
15. Percutaneous ethanol injection still has a role in small $\mathrm{HCC}<2 \mathrm{~cm}$ not suitable for thermal ablation (Level 5).

Although a meta-analysis of 5 randomized trials has shown that RFA is superior to ethanol injection in the treatment of small HCC in terms of treatment response, recurrence and OS, not all lesions are suitable for RFA (e.g., tumors near biliary tree or large vessels) [24]. For these, ethanol injection may be attempted. In Hong Kong centers, this is typically performed by injecting $90 \%$ absolute alcohol mixed with lipiodol under a general anesthesia or conscious sedation.

16. Microwave ablation is a safe and effective modality for treatment of HCC. It is an alternative option to RFA (Level 4).

In Asia, microwave ablation is used as an alternative to RFA, with several studies reporting similar safety and efficacy outcomes [25-28]. In animal models, lesions that have been subjected to microwave ablation showed significantly less blood vessel-mediated cooling than lesions after RFA, suggesting that microwave ablation may lead to fewer tumor recurrences in the long term $[29,30]$.

17. High-intensity focused ultrasound (HIFU) ablation is safe and effective in the treatment of small HCCs. It can achieve survival outcomes comparable to those of RFA and thus serves as a good alternative treatment (Level 4).

18. HIFU ablation is generally well tolerated in HCC patients with Child-Pugh A/B cirrhosis. It may have some advantage in selected patients, such as those with ascites or with tumors close to major bile ducts (Level 4).

19. HIFU may be used as an alternative bridging therapy for HCC patients awaiting liver transplantation (Level 4).

HIFU has been compared to RFA in 2 case series with small or recurrent HCC, with similar outcomes between the 2 techniques [31, 32]. HIFU is a well-tolerated treatment for HCC in patients with cirrhosis and ascites [31], and data from a retrospective study showed that significantly more HIFU-bridged patients had a complete response to treatment compared with TACE-treated patients [33].

20. Patients with a predominant large mass in one lobe and 1 or 2 small tumor nodules in the other lobe may benefit from combined resection of the predominant tumor and resection or ablation of the contralateral nodules (Level 4).

Recent studies have shown that hepatectomy combined with RFA $[13,34]$ or other forms of ablation [35] is an effective, well-tolerated treatment for selected patients with multifocal disease.

\section{Role of TACE}

21. TACE is recommended as a first-line treatment for patients with unresectable, large/ multifocal HCCs, with no vascular invasion or extrahepatic spread, and with satisfactory liver function (Child-Pugh A or B) (Level 1).

22. Selective or super-selective TACE should be attempted in order to preserve nontumorous liver parenchyma, maximize treatment effect, and minimize complications (Level 5).

23. Selective TACE can be performed in patients with small tumors in whom ablation is difficult to perform because of tumor location or medical comorbidities (Level 5). In Hong Kong, TACE has emerged as the "standard" therapy for patients with unresectable HCC and Child-Pugh A/B cirrhosis, and its safety and efficacy in this population is supported by 2 RCTs [36, 37] and 3 out of 4 meta-analyses [38-41].

24. TACE can be considered in patients with unresectable HCC with segmental portal vein invasion (Level 4). 
Although TACE has been contraindicated in HCC patients with portal vein thrombosis, several groups have reported that selective TACE can be used in these patients to improve OS [42]. However, a prospective controlled study found that the survival benefit of TACE is minimal for patients with major PVT, with a greater benefit evident for patients with segmental PVT [43].

25. TACE with drug-eluting beads (TACE-DEB) is an alternative treatment for HCC after conventional TACE fails, but there is no evidence of survival benefit over conventional TACE (Level 2).

Conventional TACE and TACE-DEB with doxorubicin-loaded beads have been compared in the PRECISION V randomized trial [44]. TACE-DEB was associated with higher rates of complete response, objective response and disease control compared with conventional TACE, but superiority was not demonstrated [44]. Based on data so far, conventional cisplatinlipiodol TACE is the standard regimen in Hong Kong, with TACE-DEB reserved for patients who fail conventional TACE or have more advanced disease.

26. TACE should be repeated at intervals of 2-3 months based on assessment of tumor status and liver function (Level 4).

27. TACE should be stopped when there is liver impairment or other serious complications; or radiologic tumor progression, despite adequate drug administration (Level 5).

28. TACE should be stopped when there is absence of viable tumor (Level 5).

In Hong Kong, the usual practice is to repeat TACE when viable residual tumor or new tumor growth is observed in a patient with good liver function. The efficacy of TACE has been found to be greater when used only when tumor growth is detected [45]; therefore, computed tomography or magnetic resonance imaging should be used to monitor therapy. Other Asian guidelines have defined TACE failure as 2-3 rounds of treatment with no response [45-47], but the specific factors that guide when to stop TACE vary among centers, and a pragmatic approach is recommended including assessments of liver function, tumor status, and the detection of events such as extrahepatic spread or venous invasion.

29. The clinical benefit of additional sorafenib to TACE is minimal. Routine combination of sorafenib and TACE is not recommended (Level 1).

Several trials have evaluated the combination of sorafenib added to TACE or TACE-DEB, but no improvements in progression or survival from the addition of sorafenib were observed [48-50].

\section{Role of TARE}

30. TARE is useful as a bridge therapy to liver transplantation in suitable candidates (Level 4).

31. TARE is useful for Child-Pugh A patients with multifocal or large burden HCC (Level 5).

32. For unresectable or unablatable HCC $>5 \mathrm{~cm}$, TARE can be considered (Level 5).

33. TARE is useful for Child-Pugh A and selected Child-Pugh B patients with small burden HCC but fail to respond to conventional TACE (Level 5).

A recent publication from a Singaporean expert group is generally representative of other guidelines for use of Y-90 TARE to treat HCC. Y-90 TARE is an option as a bridging therapy in patients with early HCC awaiting transplant, in intermediate HCC patients who have failed conventional TACE, or in advanced HCC with vascular invasion [51]. A metaanalysis of 10 studies comparing Y-90 TARE and TACE, including 2 RCTs, concluded these 2 treatments have similar effects in terms of survival, response rate and safety profile, although tumor progression is delayed after TARE [52]. A retrospective case series has found similar major and minor complication rates between TACE and TARE, but greater hospitalization for both initial procedure and readmission, and worse postembolization syndrome, with TACE [53]. There is no published cost-effectiveness study on use of Y-90 TARE for HCC; a small 


\section{Liver

randomized trial that evaluated health-related quality of life of patients with unresectable HCC did not find a significant difference between TACE and Y-90 TARE [54].

34. TARE is useful for HCC with vascular invasion, and disease is liver-dominant, and

patients have bilirubin $<2 \mathrm{mg} / \mathrm{dL}$ and Child-Pugh score $\leq 7$ (Level 4).

While survival outcomes in radioembolized patients with main portal thrombosis are poor (3-6 months), more encouraging results are seen in patients with lobar or segmental portal vein thrombosis, with median survival times of $10-14$ months after TARE $[55,56]$.

35. After unilobar TARE, it is advised to follow up the patient for at least 6 months, for possible disease downstaging and curative resection (Level 5).

Although Y-90 TARE is usually given with a palliative intent in Hong Kong, this treatment can induce tumor shrinkage or control, while promoting contralateral hypertrophy, which may permit future resection. While a systematic review of 7 studies examining contralateral hypertrophy after Y-90 TARE for diverse liver cancers found $26-47 \%$ contralateral lobe hypertrophy at 44 days to 9 months, this review is limited by the heterogeneity of the diseases treated, dose and delivery of Y-90 TARE, and time to measurement of hypertrophy. An analysis compared hypertrophy induced by PVE or Y-90 TARE in 52 patients with liver malignancies, pair-matched for criteria known to influence liver growth, finding that FLR volume increase was significant in both groups (PVE, 61.5\%; Y-90 TARE, 29\%; $p<0.001$ ) [57]. Y-90 TARE may be useful for large, bulky tumors abutting essential vascular and/or biliary structures, or when the ability to achieve adequate oncological margins is a concern. Given the dynamic nature of tumor response, ipsilateral lobe atrophy, contralateral lobe hypertrophy, disease progression (e.g., formation of new lesions in untreated lobe, extrahepatic metastases), and potential complications such as portal hypertension and hypersplenism, we recommend patients are followed-up after Y-90 TARE clinically and with imaging to investigate possible disease downstaging and curative resection.

Two recent phase III trials have compared Y-90 TARE with sorafenib with consistent results in patients with advanced HCC, a population with poor prognosis. In both trials, Y-90 TARE showed a higher tumor response rate in the initial phase and a better adverse event profile than sorafenib, but neither trial showed a statistically significant difference in survival between treatment arms $[58,59]$.

\section{Role of External Radiotherapy}

36. SBRT is an acceptable option for unresectable HCC (up to 5 lesions) (Level 4).

37. SBRT can be considered for patients with limited liver reserve (up to Child-Pugh Grade B8 and platelet count $\geq 50 \times 10^{9} / \mathrm{L}$ ).

38. SBRT can be an alternative to ablation for tumors close to major blood vessels or biliary duct (Level 5).

39. Local control can be achieved by SBRT with limited toxicities (Level 4).

40. SBRT can be considered as a bridging therapy before liver transplantation (Level 4).

In Hong Kong, the majority of HCC patients are inoperable (for resection or transplantation) at the time of diagnosis, and some tumor factors such as size $(>5 \mathrm{~cm})$, location, or portal vein invasion may preclude use of nonsurgical RFA. Historically, radiation therapy for liver metastases has been limited by the risk of radiation-induced liver disease, but new developments in SBRT reduce these limitations by using real-time stereotactic 3D tracking of organ and tumor position to deliver high-dose radiation to the tumor while minimizing excessive irradiation of the remaining liver and surrounding tissues. SBRT is typically delivered as several fractions (range, 1-6) over 1-2 weeks.

A review of published data on liver-directed SBRT including numerous retrospective and prospective phase I and phase II studies has demonstrated the safety and efficacy of SBRT [60]. SBRT for hepatic malignancies has been evaluated in a phase I/II study including 26 


\section{Liver
Cancer}

\begin{tabular}{l|l}
\hline Liver Cancer 2018;7:40-54 \\
\hline DOI: 10.1159/000485984 & $\begin{array}{l}\text { @ 2018 S. Karger AG, Basel } \\
\text { www.karger.com/lic }\end{array}$ \\
\hline
\end{tabular}

Cheung et al.: Consensus Statements for the Management of Unresectable HCC

patients which reported a median survival of 11.1 months, and 1-year OS rate of $45 \%$, with adverse events including a decline in Child-Pugh score in 9 patients and 2 grade 5 hepatic failures [61]. A small study has also evaluated SBRT as a bridge to transplantation, concluding it is a feasible and well-tolerated bridging therapy which may prolong a patient's candidacy for a curative liver transplant [62].

Patient selection criteria for SBRT in Hong Kong centers typically includes: Child-Pugh score of B8 or below; up to 5 lesions; uninvolved liver volume $\geq 700 \mathrm{~mL}$ (not compulsory); and platelet count $\geq 50 \times 10^{9} / \mathrm{L}$. Repeated SBRT can be considered for new lesions in the liver not previously irradiated (time interval from last SBRT should be preferably 6 months or longer). Radiation is usually delivered in an individualized dose according to tumor volume, liver reserve, and technique. The dose may be up to $5 \times 10 \mathrm{~Gy}$, if dose constraints to the rest of liver or other normal organs can be met.

Data on SBRT in HCC patients with a Child-Pugh score of B8 and above are scarce due to the poor prognosis of this population. While some studies have suggested avoiding SBRT in patients with Child-Pugh score of B8 and above except as a bridge to transplant $[63,64]$, other studies of SBRT have included small numbers of such patients with encouraging results [65, 66]. A recent consensus statement recommends that SBRT be used with caution in all ChildPugh B patients and only at low-dose volumes [67]. Clinical practice in Hong Kong is to treat selected Child-Pugh B8 patients with SBRT at the discretion of the treating physicians.

\section{Role of Chemotherapy}

41. There are inadequate data to establish chemotherapy as a standard treatment for advanced HCC.

42. FOLFOX and SECOX regimens are feasible options in selected fit patients with advanced, unresectable HCC (Level 5).

In a randomized trial comparing doxorubicin to no antitumor therapy in inoperable HCC, patients receiving doxorubicin had a survival benefit versus those receiving no antitumor therapy (10.6 vs. 7.5 weeks, respectively) but with fatal complications in $25 \%$ of patients [68]. Several trials have evaluated recombinant alpha-interferon ( $\alpha$-IFN) for HCC in Asian and Western patients. A randomized trial comparing doxorubicin with $\alpha$-IFN in Asian patients found $\alpha$-IFN induced better tumor regression and fewer serious or fatal complications [69], and a trial comparing $\alpha$-IFN with no antitumor therapy found $\alpha$-IFN improved survival and induced tumor regression [70]. $\alpha$-IFN was compared with symptomatic treatment in a randomized trial in a Western population with HCC [71]; $\alpha$-IFN did not modify the probability of progression and was not well tolerated in patients with cirrhosis.

Cisplatin/ $\alpha$-IFN/doxorubicin/fluorouracil (PIAF) combination therapy was compared with doxorubicin in HCC, with PIAF-treated patients having a nonsignificantly higher response rate and better survival than doxorubicin-treated patients [72]. However, PIAF was associated with higher treatment-related toxicity [72].

A randomized phase III trial compared sorafenib plus doxorubicin with doxorubicin alone in HCC, with sorafenib plus doxorubicin resulting in improvements to median time to progression, OS and progression-free survival (PFS) compared with doxorubicin [73]. Sorafenib has been compared with sorafenib plus doxorubicin in HCC in a recent phase III study, which found that the addition of doxorubicin resulted in higher toxicity, but did not improve OS or PFS [74].

Modified infusional fluorouracil, leucovorin, and oxaliplatin (FOLFOX4) has been compared with doxorubicin as palliative chemotherapy for HCC [75]. No significant differences in toxicities were observed, and although the trial did not meet its primary endpoint, a trend toward improved OS with FOLFOX4 was observed [75], and Chinese treatment guidelines for HCC recommend FOLFOX4 for advanced HCC patients [76]. 
Despite numerous trials, there are insufficient data to routinely recommend any chemotherapy regimen in HCC, and no such agent has been approved. Chemotherapy can be considered for patients who have failed to respond to sorafenib, providing performance status and organ functions are sufficient to tolerate it. A sorafenib, oxaliplatin, capecitabine (SECOX) regimen was evaluated in phase II study of 51 HCC patients with promising results [77], and a phase III study is ongoing [78]. Although the evidence base is limited, in Hong Kong FOLFOX4 or SECOX regimens have been adopted in some centers for advanced HCC patients with good results, especially in patients with lung metastases.

\section{Role of Targeted Therapy}

43. Sorafenib is currently the standard first-line systemic treatment for HCC with Child-

Pugh A liver function who are not suitable for surgery, locoregional therapy or transarterial therapy (Level 2).

44. Regorafenib is an option for second-line treatment for patients who developed

progressive disease to sorafenib treatment (Level 2).

Sorafenib has become a standard treatment for HCC in Asia and elsewhere, based on large RCTs which demonstrated a modest survival advantage [79, 80], although subgroup analyses of these data show the survival benefit is reduced in the presence of HBV infection [81, 82]. A phase III placebo-controlled trial has found regorafenib can improve survival of sorafenibrefractory patients by 2 months compared with placebo, with the commonly-reported adverse events including grade 3 diarrhea, hypertension, increased bilirubin, and hand-foot skin reactions $(3,16,11$, and $11 \%$ of patients, respectively) [83]. Additional phase III trials in this population are ongoing, and while results of second-line therapy trials are encouraging, the patients enrolled in these trials are often selected for better liver function and patient performance, and thus may not be representative of sorafenib-refractory patients encountered in clinical practice. The clinical experience with sorafenib in Hong Kong is consistent with the modest benefits seen in the studies.

A recent phase III trial has compared the multikinase inhibitors lenvatinib and sorafenib as a first-line treatment in patients with unresectable HCC [84]. Lenvatinib was noninferior to sorafenib for OS, and similar numbers of patients in both arms experienced treatmentemergent adverse events [84]. Patients in the lenvatinib arm had statistically significant improvements in PFS [84], time to progression, and objective response rate, suggesting lenvatinib may be a treatment option for advanced HCC.

\section{Role of Immunotherapy}

45. Anti-PD1 therapy is potentially a second-line or subsequent line of treatment in patients with sorafenib-refractory disease (Level 3).

In recent years, there has been considerable interest in therapeutically targeting immunoregulatory checkpoints to stimulate the immune system to attack tumors. HCC is an inflammation associated cancer and can be immunogenic [85], and HBV and HCV infection are associated with upregulation of circulating T-cell inhibitory receptor programmed cell death protein 1 (PD1) [86, 87]. In a study of HBV-associated HCC patients, upregulation of PD1 and its ligand (PD-L1) are associated with poor outcomes [88], and higher intratumoral expression of PD-L1 is associated with poorer disease-free survival and OS after hepatectomy [89]. Preclinical and clinical studies have shown that blockade of the PD1 pathway can induce tumor regression in various tumor types [90], and PD1 blockade with monoclonal antibodies has extended survival in mouse models of HCC [91, 92].

A phase I/II open-label dose-escalation trial has evaluated nivolumab, a humanized monoclonal antibody to PD1, in unresectable HCC patients who have good liver function, and have had disease progression on sorafenib [93]. Safety profile was similar to what has been 
observed in other tumor types without any new safety signals [93]. Nivolumab maintained a manageable tolerability profile during escalation with common adverse events including fatigue, pruritus, rash, and diarrhea [93]. Objective responses were durable irrespective of HBV/HCV status, prior sorafenib treatment, or PD-L1 expression on tumor cells, and OS rate was encouraging [93]. Based on durable objective responses observed in a 154-patient subgroup of this trial, nivolumab was recently approved by the US Food and Drug Administration for HCC patients who have been previously treated with sorafenib [94]. A phase III study of nivolumab in patients with advanced HCC is ongoing [95], and future studies may identify biomarkers that predict response to anti-PD1/PD-L1 therapy.

\section{Conclusions}

These treatment guidelines integrate the latest evidence and expert opinion from physicians with a high level of experience in the management of HCC patients. Compared to other guidelines, we advocate a broader use of surgical resection, and distinct from other groups, our guidelines incorporate the HKLC staging system, which has shown favorable results in prognosis and guiding treatment in both Asian and non-Asian populations.

Our statements offer detailed guidance on assessing patient suitability for resection and techniques for increasing FLR; use of transplantation and guidance for antiviral therapy to reduce HCC incidence are summarized in the 2015 recommendations. Our recommendations for local ablation, TACE and TARE represent an evolution of the statements from the 2015 document. The emergence of sorafenib as a standard therapy and regorafenib as an emerging treatment for HCC is recognized, and the potential for immunotherapy is noted.

\section{Acknowledgement}

The authors would like to thank Dr. Alister Smith, Cassandra Thomson, and Dr. Jose Miguel (Awi) Curameng of MIMS (Hong Kong) Limited for providing medical writing and editing support, which was funded by BTG International Asia Ltd. and Sirtex Medical Singapore Pte Ltd. The meetings during which these consensus points were formulated and discussed were supported by an unrestricted educational grant funded equally by BTG International Asia Ltd. and Sirtex Medical Singapore Pte Ltd.

\section{Disclosure Statement}

The authors have no conflicts of interest to declare.

\section{Funding Sources}

The meetings during which these consensus points were formulated and discussed were supported by an unrestricted educational grant funded equally by BTG International Asia Ltd and Sirtex Medical Singapore Pte Ltd. 


\section{References}

1 Zhu RX, Seto WK, Lai CL, Yuen MF: Epidemiology of hepatocellular carcinoma in the Asia-Pacific region. Gut Liver 2016;10:332-339.

2 Hong Kong Cancer Registry: Top Ten Cancers in 2014. http://www3.ha.org.hk/cancereg/pdf/top10/ rank_2014.pdf (accessed May 18, 2017).

3 Llovet JM, Bru C, Bruix J: Prognosis of hepatocellular carcinoma: the BCLC staging classification. Semin Liver Dis 1999;19:329-338.

4 Yau T, Tang VY, Yao TJ, Fan ST, Lo CM, Poon RT: Development of Hong Kong Liver Cancer staging system with treatment stratification for patients with hepatocellular carcinoma. Gastroenterology 2014;146:1691-700e3.

5 Poon RT, Cheung TT, Kwok PC, Lee AS, Li TW, Loke KL, Chan SL, Cheung MT, Lai TW, Cheung CC, Cheung FY, Loo CK, But YK, Hsu SJ, Yu SC, Yau T: Hong Kong consensus recommendations on the management of hepatocellular carcinoma. Liver Cancer 2015;4:51-69.

6 Oxford Centre for Evidence-Based Medicine Levels of Evidence Working Group: The Oxford 2011 Levels of Evidence. http://www.cebm.net/index.aspx?o=5653 (accessed May 18, 2017).

7 Yan X, Fu X, Cai C, Zi X, Yao H, Qiu Y: Validation of models in patients with hepatocellular carcinoma: comparison of Hong Kong Liver Cancer with Barcelona Clinic Liver Cancer staging system in a Chinese cohort. Eur J Gastroenterol Hepatol 2015;27:1180-1186.

8 Sohn JH, Duran R, Zhao Y, Fleckenstein F, Chapiro J, Sahu S, Schernthaner RE, Qian T, Lee H, Zhao L, Hamilton J, Frangakis C, Lin M, Salem R, Geschwind JF: Validation of the Hong Kong Liver Cancer Staging System in determining prognosis of the North American patients following intra-arterial therapy. Clin Gastroenterol Hepatol 2017; 15:746-755e4.

9 Chok KS, Cheung TT, Chan SC, Poon RT, Fan ST, Lo CM: Surgical outcomes in hepatocellular carcinoma patients with portal vein tumor thrombosis. World J Surg 2014;38:490-496.

10 Fan ST: Liver functional reserve estimation: state of the art and relevance for local treatments: the Eastern perspective. J Hepatobiliary Pancreat Sci 2010;17:380-384.

11 Azoulay D, Castaing D, Smail A, Adam R, Cailliez V, Laurent A, Lemoine A, Bismuth H: Resection of nonresectable liver metastases from colorectal cancer after percutaneous portal vein embolization. Ann Surg 2000; 231:480-486.

12 Kubota K, Makuuchi M, Kusaka K, Kobayashi T, Miki K, Hasegawa K, Harihara Y, Takayama T: Measurement of liver volume and hepatic functional reserve as a guide to decision-making in resectional surgery for hepatic tumors. Hepatology 1997;26:1176-1181.

13 Cheung TT, Ng KK, Chok KS, Chan SC, Poon RT, Lo CM, Fan ST: Combined resection and radiofrequency ablation for multifocal hepatocellular carcinoma: prognosis and outcomes. World J Gastroenterol 2010;16:3056-3062.

14 Fan ST, Mau Lo C, Poon RTP, Yeung C, Leung Liu C, Yuen WK, Ming Lam C, Ng KKC, Ching Chan S: Continuous improvement of survival outcomes of resection of hepatocellular carcinoma: a 20-year experience. Ann Surg 2011;253:745-758.

15 Poon RT-P, Fan ST, Wong J: Selection criteria for hepatic resection in patients with large hepatocellular carcinoma larger than $10 \mathrm{~cm}$ in diameter. J Am Coll Surg 2002;194:592-602.

16 Glantzounis GK, Tokidis E, Basourakos SP, Ntzani EE, Lianos GD, Pentheroudakis G: The role of portal vein embolization in the surgical management of primary hepatobiliary cancers. A systematic review. Eur J Surg Oncol 2017;43:32-41.

17 Chan AC, Chok K, Dai JW, Lo CM: Impact of split completeness on future liver remnant hypertrophy in associating liver partition and portal vein ligation for staged hepatectomy (ALPPS) in hepatocellular carcinoma: complete-ALPPS versus partial-ALPPS. Surgery 2017;161:357-364.

18 Duan C, Liu M, Zhang Z, Ma K, Bie P: Radiofrequency ablation versus hepatic resection for the treatment of early-stage hepatocellular carcinoma meeting Milan criteria: a systematic review and meta-analysis. World J Surg Oncol 2013;11:190.

19 Lu Z, Wen F, Guo Q, Liang H, Mao X, Sun H: Radiofrequency ablation plus chemoembolization versus radiofrequency ablation alone for hepatocellular carcinoma: a meta-analysis of randomized-controlled trials. Eur J Gastroenterol Hepatol 2013;25:187-194.

20 Poon RT, Ng KK, Lam CM, Ai V, Yuen J, Fan ST: Effectiveness of radiofrequency ablation for hepatocellular carcinomas larger than $3 \mathrm{~cm}$ in diameter. Arch Surg 2004;139:281-287.

21 Huang JW, Hernandez-Alejandro R, Croome KP, Yan LN, Wu H, Chen ZY, Prasoon P, Zeng Y: Surgical vs percutaneous radiofrequency ablation for hepatocellular carcinoma in dangerous locations. World J Gastroenterol 2011;17:123-129.

22 Khan MR, Poon RT, Ng KK, Chan AC, Yuen J, Tung H, Tsang J, Fan ST: Comparison of percutaneous and surgical approaches for radiofrequency ablation of small and medium hepatocellular carcinoma. Arch Surg 2007;142: 1136-1143; discussion 1143.

23 Wang X, Sofocleous CT, Erinjeri JP, Petre EN, Gonen M, Do KG, Brown KT, Covey AM, Brody LA, Alago W, Thornton RH, Kemeny NE, Solomon SB: Margin size is an independent predictor of local tumor progression after ablation of colon cancer liver metastases. Cardiovasc Interv Radiol 2013;36:166-175.

24 Orlando A, Leandro G, Olivo M, Andriulli A, Cottone M: Radiofrequency thermal ablation vs. percutaneous ethanol injection for small hepatocellular carcinoma in cirrhosis: meta-analysis of randomized controlled trials. Am J Gastroenterol 2009;104:514-524. 
25 Dong B, Liang P, Yu X, Su L, Yu D, Cheng Z, Zhang J: Percutaneous sonographically guided microwave coagulation therapy for hepatocellular carcinoma: results in 234 patients. AJR Am J Roentgenol 2003;180:15471555.

26 Shibata T, Iimuro Y, Yamamoto Y, Maetani Y, Ametani F, Itoh K, Konishi J: Small hepatocellular carcinoma: comparison of radio-frequency ablation and percutaneous microwave coagulation therapy. Radiology 2002; 223:331-337.

27 Xu HX, Xie XY, Lu MD, Chen JW, Yin XY, Xu ZF, Liu GJ: Ultrasound-guided percutaneous thermal ablation of hepatocellular carcinoma using microwave and radiofrequency ablation. Clin Radiol 2004;59:53-61.

28 Lee KF, Hui JW, Cheung YS, Wong JS, Chong CN, Wong J, Yu SC, Lai PB: Surgical ablation of hepatocellular carcinoma with 2.45-GHz microwave: a critical appraisal of treatment outcomes. Hong Kong Med J 2012;18: 85-91.

29 Bhardwaj N, Dormer J, Ahmad F, Strickland AD, Gravante G, West K, Dennison AR, Lloyd DM: Microwave ablation of the liver: a description of lesion evolution over time and an investigation of the heat sink effect. Pathology 2011;43:725-731.

30 Wright AS, Sampson LA, Warner TF, Mahvi DM, Lee FT Jr: Radiofrequency versus microwave ablation in a hepatic porcine model. Radiology 2005;236:132-139.

31 Cheung TT, Fan ST, Chu FS, Jenkins CR, Chok KS, Tsang SH, Dai WC, Chan AC, Chan SC, Yau TC, Poon RT, Lo CM: Survival analysis of high-intensity focused ultrasound ablation in patients with small hepatocellular carcinoma. HPB 2013;15:567-573.

32 Chan AC, Cheung TT, Fan ST, Chok KS, Chan SC, Poon RT, Lo CM: Survival analysis of high-intensity focused ultrasound therapy versus radiofrequency ablation in the treatment of recurrent hepatocellular carcinoma. Ann Surg 2013;257:686-692.

33 Cheung TT, Fan ST, Chan SC, Chok KS, Chu FS, Jenkins CR, Lo RC, Fung JY, Chan AC, Sharr WW, Tsang SH, Dai WC, Poon RT, Lo CM: High-intensity focused ultrasound ablation: an effective bridging therapy for hepatocellular carcinoma patients. World J Gastroenterol 2013;19:3083-3089.

34 Choi D, Lim HK, Joh JW, Kim SJ, Kim MJ, Rhim H, Kim YS, Yoo BC, Paik SW, Park CK: Combined hepatectomy and radiofrequency ablation for multifocal hepatocellular carcinomas: long-term follow-up results and prognostic factors. Ann Surg Oncol 2007; 14:3510-3518.

35 Liu CL, Fan ST, Lo CM, Ng IO, Poon RT, Wong J: Hepatic resection for bilobar hepatocellular carcinoma: is it justified? Arch Surg 2003;138:100-104.

36 Lo CM, Ngan H, Tso WK, Liu CL, Lam CM, Poon RT, Fan ST, Wong J: Randomized controlled trial of transarterial lipiodol chemoembolization for unresectable hepatocellular carcinoma. Hepatology 2002;35:1164-1171.

37 Llovet JM, Real MI, Montana X, Planas R, Coll S, Aponte J, Ayuso C, Sala M, Muchart J, Sola R, Rodes J, Bruix J: Arterial embolisation or chemoembolisation versus symptomatic treatment in patients with unresectable hepatocellular carcinoma: a randomised controlled trial. Lancet 2002;359:1734-1739.

38 Llovet JM, Bruix J: Systematic review of randomized trials for unresectable hepatocellular carcinoma: Chemoembolization improves survival. Hepatology 2003;37:429-442.

39 Marelli L, Stigliano R, Triantos C, Senzolo M, Cholongitas E, Davies N, Tibballs J, Meyer T, Patch DW, Burroughs AK: Transarterial therapy for hepatocellular carcinoma: which technique is more effective? A systematic review of cohort and randomized studies. Cardiovasc Interv Radiol 2007;30:6-25.

40 Camma C, Schepis F, Orlando A, Albanese M, Shahied L, Trevisani F, Andreone P, Craxi A, Cottone M: Transarterial chemoembolization for unresectable hepatocellular carcinoma: meta-analysis of randomized controlled trials. Radiology 2002;224:47-54.

41 Oliveri RS, Wetterslev J, Gluud C: Transarterial (chemo)embolisation for unresectable hepatocellular carcinoma. Cochrane Database Syst Rev 2011;CD004787.

42 Quirk M, Kim YH, Saab S, Lee EW: Management of hepatocellular carcinoma with portal vein thrombosis. World J Gastroenterol 2015;21:3462-3471.

43 Niu ZJ, Ma YL, Kang P, Ou SQ, Meng ZB, Li ZK, Qi F, Zhao C: Transarterial chemoembolization compared with conservative treatment for advanced hepatocellular carcinoma with portal vein tumor thrombus: using a new classification. Med Oncol 2012;29:2992-2997.

44 Lammer J, Malagari K, Vogl T, Pilleul F, Denys A, Watkinson A, Pitton M, Sergent G, Pfammatter T, Terraz S, Benhamou Y, Avajon Y, Gruenberger T, Pomoni M, Langenberger H, Schuchmann M, Dumortier J, Mueller C, Chevallier P, Lencioni R: Prospective randomized study of doxorubicin-eluting-bead embolization in the treatment of hepatocellular carcinoma: results of the PRECISION V study. Cardiovasc Interv Radiol 2010;33: $41-52$.

45 Ernst O, Sergent G, Mizrahi D, Delemazure 0, Paris JC, L'Hermine C: Treatment of hepatocellular carcinoma by transcatheter arterial chemoembolization: comparison of planned periodic chemoembolization and chemoembolization based on tumor response. AJR Am J Roentgenol 1999;172:59-64.

46 Kudo M, Matsui O, Izumi N, Kadoya M, Okusaka T, Miyayama S, Yamakado K, Tsuchiya K, Ueshima K, Hiraoka A, Ikeda M, Ogasawara S, Yamashita T, Minami T: Transarterial chemoembolization failure/refractoriness: JSH-LCSGJ criteria 2014 update. Oncology 2014;87(suppl 1):22-31.

47 Park JW, Amarapurkar D, Chao Y, Chen PJ, Geschwind JF, Goh KL, Han KH, Kudo M, Lee HC, Lee RC, Lesmana LA, Lim HY, Paik SW, Poon RT, Tan CK, Tanwandee T, Teng G, Cheng AL: Consensus recommendations and review by an International Expert Panel on Interventions in Hepatocellular Carcinoma (EPOIHCC). Liver Int 2013;33:327-337. 
48 Kudo M, Imanaka K, Chida N, Nakachi K, Tak WY, Takayama T, Yoon JH, Hori T, Kumada H, Hayashi N, Kaneko S, Tsubouchi H, Suh DJ, Furuse J, Okusaka T, Tanaka K, Matsui O, Wada M, Yamaguchi I, Ohya T, Meinhardt G, Okita K: Phase III study of sorafenib after transarterial chemoembolisation in Japanese and Korean patients with unresectable hepatocellular carcinoma. Eur J Cancer 2011;47:2117-2127.

49 Meyer T, Fox R, Ma YT, Ross PJ, James M, Strugess R, Stubbs C, Wall L, Watkinson A, Hacking N, Evans TRJ, Collins P, Hubner R, Cunningham D, Primrose JN, Johnson PJ, Palmer DH: TACE 2: A randomized placebocontrolled, double-blinded, phase III trial evaluating sorafenib in combination with transarterial chemoembolisation (TACE) in patients with unresectable hepatocellular carcinoma (HCC) (abstract). J Clin Oncol 2016; 34(suppl):4018.

50 Lencioni R, Llovet JM, Han G, Tak WY, Yang J, Guglielmi A, Paik SW, Reig M, Kim DY, Chau GY, Luca A, del Arbol LR, Leberre MA, Niu W, Nicholson K, Meinhardt G, Bruix J: Sorafenib or placebo plus TACE with doxorubicineluting beads for intermediate stage HCC: The SPACE trial. J Hepatol 2016;64:1090-1098.

51 Lau WY, Teoh YL, Win KM, Lee RC, de Villa VH, Kim YH, Liang PC, Santos-Ocampo RS, Lo RH, Lim KB, Tai DW, Ng DC, Irani FG, Gogna A, Chow PK: Current role of selective internal radiation with yttrium-90 in liver tumors. Futur Oncol 2016;12:1193-1204.

52 Facciorusso A, Serviddio G, Muscatiello N: Transarterial radioembolization vs chemoembolization for hepatocarcinoma patients: a systematic review and meta-analysis. World J Hepatol 2016;8:770-778.

53 Lance C, McLennan G, Obuchowski N, Cheah G, Levitin A, Sands M, Spain J, Srinivas S, Shrikanthan S, Aucejo FN, Kim R, Menon KV: Comparative analysis of the safety and efficacy of transcatheter arterial chemoembolization and yttrium-90 radioembolization in patients with unresectable hepatocellular carcinoma. J Vasc Interv Radiol 2011;22:1697-1705.

54 Kolligs FT, Bilbao JI, Jakobs T, Inarrairaegui M, Nagel JM, Rodriguez M, Haug A, D'Avola D, op den Winkel M, Martinez-Cuesta A, Trumm C, Benito A, Tatsch K, Zech CJ, Hoffmann RT, Sangro B: Pilot randomized trial of selective internal radiation therapy vs. chemoembolization in unresectable hepatocellular carcinoma. Liver Int 2015;35:1715-1721.

55 Kulik LM, Carr BI, Mulcahy MF, Lewandowski RJ, Atassi B, Ryu RK, Sato KT, Benson A 3rd, Nemcek AA Jr, Gates VL, Abecassis M, Omary RA, Salem R: Safety and efficacy of 90Y radiotherapy for hepatocellular carcinoma with and without portal vein thrombosis. Hepatology 2008;47:71-81.

56 Inarrairaegui M, Thurston KG, Bilbao JI, D’Avola D, Rodriguez M, Arbizu J, Martinez-Cuesta A, Sangro B: Radioembolization with use of yttrium-90 resin microspheres in patients with hepatocellular carcinoma and portal vein thrombosis. J Vasc Interv Radiol 2010;21:1205-1212.

57 Garlipp B, de Baere T, Damm R, Irmscher R, van Buskirk M, Stubs P, Deschamps F, Meyer F, Seidensticker R, Mohnike K, Pech M, Amthauer H, Lippert H, Ricke J, Seidensticker M: Left-liver hypertrophy after therapeutic right-liver radioembolization is substantial but less than after portal vein embolization. Hepatology 2014;59: 1864-1873.

58 Chow PHW, Gandhi M; Asia-Pacific Hepatocellular Carcinoma Trials Group: Phase III multi-centre open-label randomized controlled trial of selective internal radiation therapy (SIRT) versus sorafenib in locally advanced hepatocellular carcinoma: The SIRveNIB study (abstract). J Clin Oncol 2017;35(suppl):4002.

59 Vilgrain V, Bouattour M, Sibert A, Lebtahi R, Ronot M, Pageaux GP, Guiu B, Barraud H, Silvain C, Gérolami R, Oberti F, Raoul JL, Costentin C, Samuel D, Dinut A, Pereira H, Chatellier G, Castera L; The SARAH Trial Group: SARAH: a randomised controlled trial comparing efficacy and safety of selective internal radiation therapy (with yttrium-90 microspheres) and sorafenib in patients with locally advanced hepatocellular carcinoma (abstract GS-012). J Hepatol 2017;66:S85.

60 Keane FK, Wo JY, Zhu AX, Hong TS: Liver-directed radiotherapy for hepatocellular carcinoma. Liver Cancer 2016;5:198-209.

61 Weiner AA, Olsen J, Ma D, Dyk P, DeWees T, Myerson RJ, Parikh P: Stereotactic body radiotherapy for primary hepatic malignancies - report of a phase I/II institutional study. Radiother Oncol 2016;121:79-85.

62 O'Connor JK, Trotter J, Davis GL, Dempster J, Klintmalm GB, Goldstein RM: Long-term outcomes of stereotactic body radiation therapy in the treatment of hepatocellular cancer as a bridge to transplantation. Liver Transpl 2012;18:949-954.

63 Culleton S, Jiang H, Haddad CR, Kim J, Brierley J, Brade A, Ringash J, Dawson LA: Outcomes following definitive stereotactic body radiotherapy for patients with Child-Pugh B or C hepatocellular carcinoma. Radiother Oncol 2014;111:412-417.

64 Lo C-H, Liu M-Y, Lee M-S, Yang J-F, Jen Y-M, Lin C-S, Chao H-L, Shen P-C, Huang W-Y: Comparison between Child-Turcotte-Pugh and albumin-bilirubin scores in assessing the prognosis of hepatocellular carcinoma after stereotactic ablative radiation therapy. Int J Radiat Oncol Biol Phys 2017;99:145-152.

65 Gkika E, Schultheiss M, Bettinger D, Maruschke L, Neeff HP, Schulenburg M, Adebahr S, Kirste S, Nestle U, Thimme R, Grosu A-L, Brunner TB: Excellent local control and tolerance profile after stereotactic body radiotherapy of advanced hepatocellular carcinoma. Radiat Oncol 2017;12:116.

66 Bibault J-E, Dewas S, Vautravers-Dewas C, Hollebecque A, Jarraya H, Lacornerie T, Lartigau E, Mirabel X: Stereotactic body radiation therapy for hepatocellular carcinoma: prognostic factors of local control, overall survival, and toxicity. PLoS One 2013;8:e77472.

67 Zeng Z-C, Seong J, Yoon SM, Cheng JC-H, Lam K-O, Lee A-S, Law A, Zhang J-Y, Hu Y: Consensus on stereotactic body radiation therapy for small-sized hepatocellular carcinoma at the 7th Asia-Pacific Primary Liver Cancer Expert Meeting. Liver Cancer 2017;6:264-274. 
68 Lai CL, Wu PC, Chan GC, Lok AS, Lin HJ: Doxorubicin versus no antitumor therapy in inoperable hepatocellular carcinoma. A prospective randomized trial. Cancer 1988;62:479-483.

69 Lai CL, Wu PC, Lok AS, Lin HJ, Ngan H, Lau JY, Chung HT, Ng MM, Yeoh EK, Arnold M: Recombinant alpha 2 interferon is superior to doxorubicin for inoperable hepatocellular carcinoma: a prospective randomised trial. Br J Cancer 1989;60:928-933.

70 Lai CL, Lau JY, Wu PC, Ngan H, Chung HT, Mitchell SJ, Corbett TJ, Chow AW, Lin HJ: Recombinant interferonalpha in inoperable hepatocellular carcinoma: a randomized controlled trial. Hepatology 1993;17:389-394.

71 Llovet JM, Sala M, Castells L, Suarez Y, Vilana R, Bianchi L, Ayuso C, Vargas V, Rodes J, Bruix J: Randomized controlled trial of interferon treatment for advanced hepatocellular carcinoma. Hepatology 2000;31:54-58.

72 Yeo W, Mok TS, Zee B, Leung TW, Lai PB, Lau WY, Koh J, Mo FK, Yu SC, Chan AT, Hui P, Ma B, Lam KC, Ho WM, Wong HT, Tang A, Johnson PJ: A randomized phase III study of doxorubicin versus cisplatin/interferon alpha-2b/doxorubicin/fluorouracil (PIAF) combination chemotherapy for unresectable hepatocellular carcinoma. J Natl Cancer Inst 2005;97:1532-1538.

73 Abou-Alfa GK, Johnson P, Knox JJ, Capanu M, Davidenko I, Lacava J, Leung T, Gansukh B, Saltz LB: Doxorubicin plus sorafenib vs doxorubicin alone in patients with advanced hepatocellular carcinoma: a randomized trial. JAMA 2010;304:2154-2160.

74 Abou-Alfa GK, Knox JJ, Kaubisch A, Posey J, Tan BR, Kavan P, Goel R, Murray JJ, Bekaii-Saab TS, Tam VC, Rajdev L, Kelley RK, Siegel A, Balletti J, Harding JJ, Schwartz LH, Goldberg RM, Bertagnolli MM, Venook AP: Phase III randomized study of sorafenib plus doxorubicin versus sorafenib in patients with advanced hepatocellular carcinoma (HCC): CALGB 80802 (Alliance) (abstract) . J Clin Oncol 2016;34(suppl):192.

75 Qin S, Bai Y, Lim HY, Thongprasert S, Chao Y, Fan J, Yang TS, Bhudhisawasdi V, Kang WK, Zhou Y, Lee JH, Sun Y: Randomized, multicenter, open-label study of oxaliplatin plus fluorouracil/leucovorin versus doxorubicin as palliative chemotherapy in patients with advanced hepatocellular carcinoma from Asia. J Clin Oncol 2013; 31:3501-3508.

76 Qin S: Guidelines on the diagnosis and treatment of primary liver cancer (2011 edition). Chin Clin Oncol 2012; $1: 10$.

77 Yau TC, Cheung FY, Lee F, Choo SP, Wong H, Toh H, Leung AK, Chan P, Yau TK, Wong J, Tang YF, Lau SMJ, Cheung TT, Fan ST, Poon RT-P: A multicenter phase II study of sorafenib, capecitabine, and oxaliplatin (SECOX) in patients with advanced hepatocellular carcinoma: final results of Hong Kong-Singapore Hepatocellular Carcinoma Research Collaborative Group study (abstract). J Clin Oncol 2013;31(suppl):4117.

78 ClinicalTrials.gov: Study of SECOX versus sorafenib as first-line treatment in patients with advanced hepatocellular carcinoma (HCC). https://clinicaltrials.gov/ct2/show/NCT02716766 (accessed October 25, 2017).

79 Llovet JM, Ricci S, Mazzaferro V, Hilgard P, Gane E, Blanc JF, de Oliveira AC, Santoro A, Raoul JL, Forner A, Schwartz M, Porta C, Zeuzem S, Bolondi L, Greten TF, Galle PR, Seitz JF, Borbath I, Haussinger D, Giannaris T, Shan M, Moscovici M, Voliotis D, Bruix J: Sorafenib in advanced hepatocellular carcinoma. N Engl J Med 2008; 359:378-390.

80 Cheng AL, Kang YK, Chen Z, Tsao CJ, Qin S, Kim JS, Luo R, Feng J, Ye S, Yang TS, Xu J, Sun Y, Liang H, Liu J, Wang J, Tak WY, Pan H, Burock K, Zou J, Voliotis D, Guan Z: Efficacy and safety of sorafenib in patients in the AsiaPacific region with advanced hepatocellular carcinoma: a phase III randomised, double-blind, placebocontrolled trial. Lancet Oncol 2009;10:25-34.

81 Cheng AL, Guan Z, Chen Z, Tsao CJ, Qin S, Kim JS, Yang TS, Tak WY, Pan H, Yu S, Xu J, Fang F, Zou J, Lentini G, Voliotis D, Kang YK: Efficacy and safety of sorafenib in patients with advanced hepatocellular carcinoma according to baseline status: subset analyses of the phase III Sorafenib Asia-Pacific trial. Eur J Cancer 2012; 48:1452-1465.

82 Jackson R, Psarelli EE, Berhane S, Khan H, Johnson P: Impact of viral status on survival in patients receiving sorafenib for advanced hepatocellular cancer: a meta-analysis of randomized phase III trials. J Clin Oncol 2017;35:622-628.

83 Bruix J, Qin S, Merle P, Granito A, Huang YH, Bodoky G, Pracht M, Yokosuka O, Rosmorduc O, Breder V, Gerolami R, Masi G, Ross PJ, Song T, Bronowicki JP, Ollivier-Hourmand I, Kudo M, Cheng AL, Llovet JM, Finn RS, LeBerre MA, Baumhauer A, Meinhardt G, Han G: Regorafenib for patients with hepatocellular carcinoma who progressed on sorafenib treatment (RESORCE): a randomised, double-blind, placebo-controlled, phase 3 trial. Lancet 2017;389:56-66.

84 Cheng AL, Finn RS, Qin S, Han KH, Ikeda K, Piscaglia F, Baron AD, Park J-W, Han G, Jassem J, Blanc J-F, Vogel A, Komov D, Evans TRJ, López-López C, Dutcus CE, Ren M, Kraljevic S, Tamai T, Kudo M: Phase III trial of lenvatinib (LEN) versus sorafenib (SOR) in first-line treatment of patients (pts) with unresectable hepatocellular carcinoma (uHCC) (abstract) . J Clin Oncol 2017;35(suppl):4001.

85 Hato T, Goyal L, Greten TF, Duda DG, Zhu AX: Immune checkpoint blockade in hepatocellular carcinoma: current progress and future directions. Hepatology 2014;60:1776-1782.

86 Xu P, Chen YJ, Chen H, Zhu XY, Song HF, Cao LJ, Wang XF: The expression of programmed death-1 in circulating CD4+ and CD8+ T cells during hepatitis B virus infection progression and its correlation with clinical baseline characteristics. Gut Liver 2014;8:186-195.

87 Barathan M, Gopal K, Mohamed R, Ellegard R, Saeidi A, Vadivelu J, Ansari AW, Rothan HA, Ravishankar Ram M, Zandi K, Chang LY, Vignesh R, Che KF, Kamarulzaman A, Velu V, Larsson M, Kamarul T, Shankar EM: Chronic hepatitis $C$ virus infection triggers spontaneous differential expression of biosignatures associated with $\mathrm{T}$ cell exhaustion and apoptosis signaling in peripheral blood mononucleocytes. Apoptosis 2015;20:466-480. 
88 Zeng Z, Shi F, Zhou L, Zhang MN, Chen Y, Chang XJ, Lu YY, Bai WL, Qu JH, Wang CP, Wang H, Lou M, Wang FS, $\mathrm{Lv}$ JY, Yang YP: Upregulation of circulating PD-L1/PD-1 is associated with poor post-cryoablation prognosis in patients with HBV-related hepatocellular carcinoma. PLoS One 2011;6:e23621.

89 Gao Q, Wang XY, Qiu SJ, Yamato I, Sho M, Nakajima Y, Zhou J, Li BZ, Shi YH, Xiao YS, Xu Y, Fan J: Overexpression of PD-L1 significantly associates with tumor aggressiveness and postoperative recurrence in human hepatocellular carcinoma. Clin Cancer Res 2009;15:971-979.

90 Pardoll DM: The blockade of immune checkpoints in cancer immunotherapy. Nat Rev Cancer 2012;12:252264.

91 Chen Y, Ramjiawan RR, Reiberger T, Ng MR, Hato T, Huang Y, Ochiai H, Kitahara S, Unan EC, Reddy TP, Fan C, Huang P, Bardeesy N, Zhu AX, Jain RK, Duda DG: CXCR4 inhibition in tumor microenvironment facilitates antiprogrammed death receptor-1 immunotherapy in sorafenib-treated hepatocellular carcinoma in mice. Hepatology 2015;61:1591-1602.

92 Morales-Kastresana A, Sanmamed MF, Rodriguez I, Palazon A, Martinez-Forero I, Labiano S, Hervas-Stubbs S, Sangro B, Ochoa C, Rouzaut A, Azpilikueta A, Bolanos E, Jure-Kunkel M, Gutgemann I, Melero I: Combined immunostimulatory monoclonal antibodies extend survival in an aggressive transgenic hepatocellular carcinoma mouse model. Clin Cancer Res 2013;19:6151-6162.

93 El-Khoueiry AB, Sangro B, Yau T, Crocenzi TS, Kudo M, Hsu C, Kim TY, Choo SP, Trojan J, Welling THR, Meyer T, Kang YK, Yeo W, Chopra A, Anderson J, Dela Cruz C, Lang L, Neely J, Tang H, Dastani HB, Melero I: Nivolumab in patients with advanced hepatocellular carcinoma (CheckMate 040): an open-label, non-comparative, phase 1/2 dose escalation and expansion trial. Lancet 2017;389:2492-2502.

94 Food and Drug Administration (USA): FDA grants accelerated approval to nivolumab for HCC previously treated with sorafenib. https://www.fda.gov/Drugs/InformationOnDrugs/ApprovedDrugs/ucm577166.htm (accessed October 26, 2017).

95 ClinicalTrials.gov: An investigational immuno-therapy study of nivolumab compared to sorafenib as a first treatment in patients with advanced hepatocellular carcinoma. https://clinicaltrials.gov/ct2/show/ NCT02576509 (accessed June 7, 2017). 